\title{
P-GLYCOPROTEIN EFFECTS ON DRUGS PHARMACOKINETICS AND DRUG-DRUG- INTERACTIONS AND THEIR CLINICAL IMPLICATIONS
}

Anwar Anwar Mohamed1, Ayman O.S. El-Kadi1, 1) Faculty of Pharmacy and Pharmaceutical Sciences, University of Alberta, Edmonton, Alberta, Canada T6G 2E1

Received: 1 May 2012, Accepted in revised form: 23 May 2012, Published: 29 May 2012

Corresponding author: Ayman O.S. El-Kadi, e- mail: aelkadi@pharmacy.ualberta.ca

\section{ABSTRACT:}

During the last couple of decades, efflux transporters have received considerable attention due to their ability to alter, either beneficially or detrimentally the pharmacokinetic and pharmacodynamic for an administered drug. The expression of the energy dependent transporter, member of the ATP binding cassette $(\mathrm{ABC})$ transporters superfamily, is not only limited to cancerous tissues, but is also expressed in different normal tissues and barriers such as the blood brain barrier and placenta. Furthermore, its unique distribution at the sites of absorption such as small intestine has been shown to greatly affect the bioavailability of the drug-substrates, and thus altering their effect. In addition, the striking overlap of substrates between P-glycoprotein (P-gp) and the phase I enzyme cytochrome P450 3A4 (CYP3A4) in addition to their coexistence at the same site has been shown to act synergistically to decrease oral drug bioavailability. Interestingly, the co-administration of a drug-substrate and an inhibitor of P-gp have been shown to increase the plasma concentration of the drug-substrates causing lethal toxicities that warrants critical evaluation of drugs as whether or not they could be substrates or inhibitors to P-gp. The availability of various in vitro cell culture models and in vivo knockout models of P-gp are currently serving the pharmaceutical sciences community to deliver safer drug use and lower risks of drug-drug interactions based on P-gp interactions. Therefore, the purpose of the current review is to summarize the current knowledge about the role of P-gp in determining drug ADME profile, and its role in drug-druginteractions and their clinical implications.

Key words: P-glycoprotein, Efflux transporters, Pharmacokinetics, Metabolism, Drug-Drug interactions.

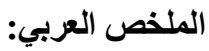

$$
\begin{aligned}
& \text { تأثيرات البروتين السكري-بي على حركية الأدوية والتذاخلات الدوائية وآثار ها السريرية } \\
& \text { أيمن عودة سعيد القاضي 1، أنور أنور محمد } 1
\end{aligned}
$$

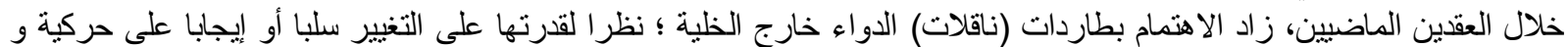

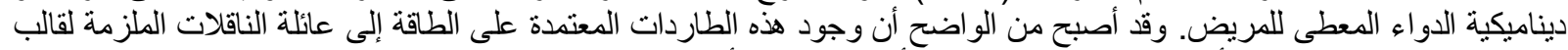

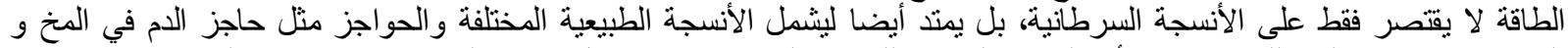

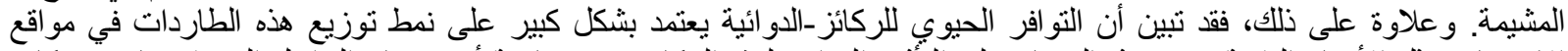

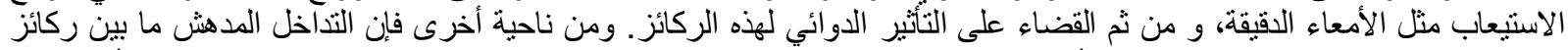

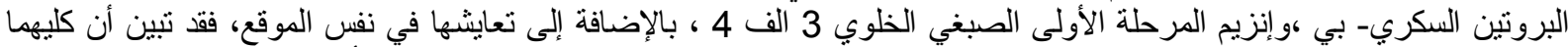

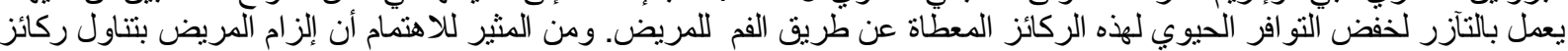

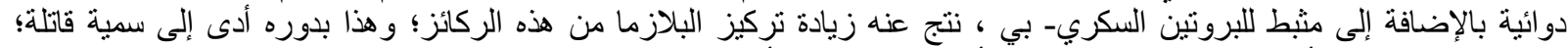

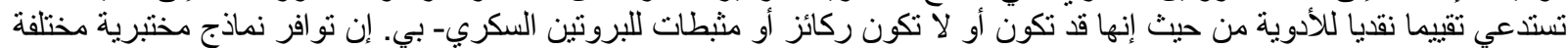

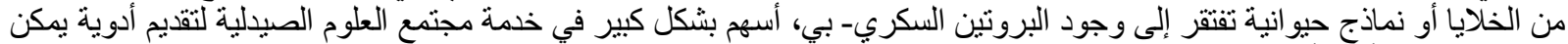

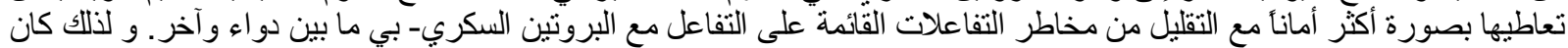

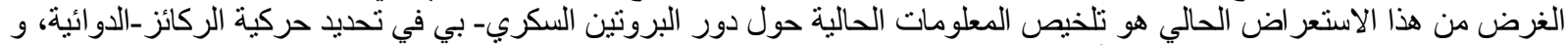

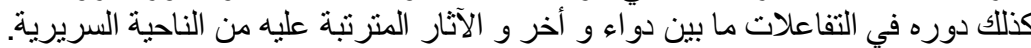
الكلمات المفتاحية: البروتين السكري-بي، طاردات الدواءواء، حركية الدواء، الأيض، التداخلات الدية الدوائية.

Copyright $\odot 2012$ AA Mohamed \& AOS El-Kadi and LJPCP. This is an open access article distributed under the Creative Commons Attribution 3.0 License, which permits unrestricted use, distribution, and reproduction in any medium, provided the original work is properly cited. 


\section{INTRODUCTION:}

$\neg$ ransport proteins operating in the efflux direction have received considerable attention in the last couple of decades within the pharmaceutical sciences community. The importance of these proteins emerges from their ability to alter, either beneficially or detrimentally, the pharmacokinetic and pharmacodynamic events for an administered drug. In general, these transporters are divided into two categories: solute carrier superfamily (SLC), and ATP-binding cassette transporters superfamily $(\mathrm{ABC})$ [1]. The $\mathrm{ABC}$ transporters superfamily is further divided to $\mathrm{P}$-glycoprotein (also known as P-gp, MDR1, ABCB1), multidrug resistance-associated proteins (MRPs) containing 9 members (MRPs1-9), and breast cancer resistance protein (BCRP, ABCG2) [2]. Some if not all of these transporters have been recently recognized as important determinants of variability in drug disposition and subsequently its responses. According to literature, the number of published studies and patents involving transporters has increased dramatically over the last 25 years. Importantly, studies and patents involving P-gp have gained more attention than other studies due to its vital role in drug disposition [3]. P-gp was first identified by Juliano and Ling in multi-drug resistant Chinese hamster ovary cells, but not in the wild-type drug sensitive cells [4]. This discovery led to two important findings, the first of which is that P-gp is an energy dependent efflux transporter driven by ATP hydrolysis [5]. The second is that P-gp was found to be expressed in cancerous tissues in addition to a variety of normal tissues, in human and rodents, including adrenal gland, kidney, liver, lung, brain, lung, intestine, testes, and eye [6]. The gene encoding $\mathrm{P}$-gp is $\mathrm{ABCB} 1$, and the translated transcript of this gene is a $170 \mathrm{kDa}$ protein, comprising 1280 amino acids, and having 2 ATP-binding cassettes and 12 transmembrane domains across the cellular lipid bilayer [6]. The P-gp was found to be localized on the canalicular surface of hepatocytes in the liver [7], the apical surface of epithelial cells of proximal tubules in the kidneys [8], columnar epithelial cells of the intestine [9], epithelial cells of placenta [10], and the luminal surface of capillary endothelial cells in brain and testes ,Fig1. [11].

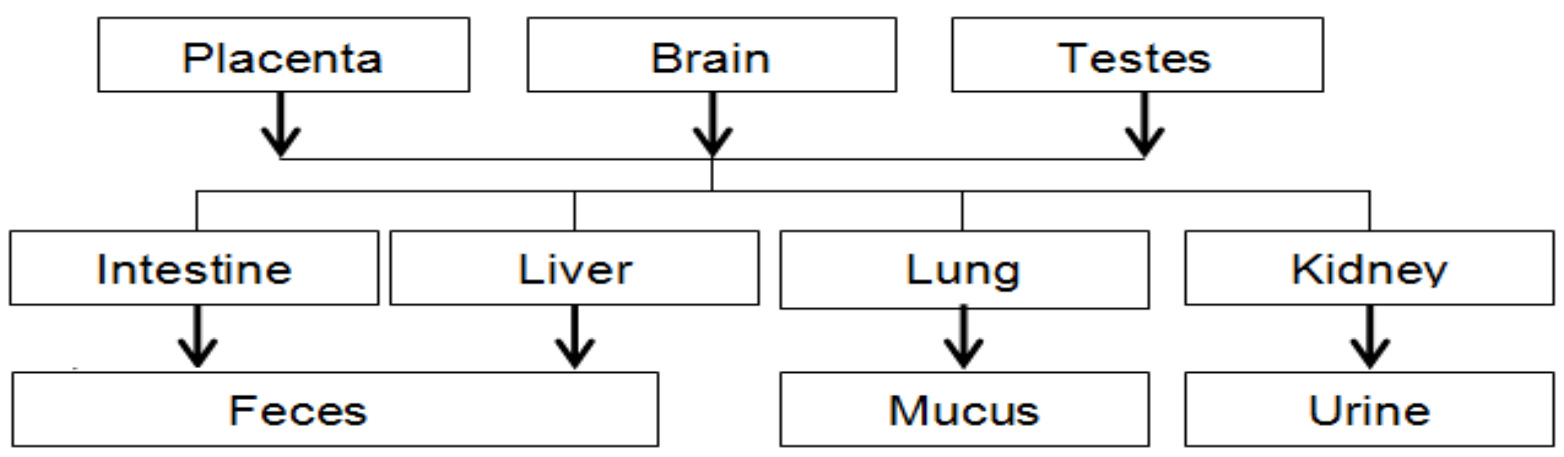

Figure1. Internal organs known to have P-GP expressed and the direction of the substrates of P-GP in various organs of the body. The bold solid arrows indicate presence of P-GP and the direction of efflux. Modified from reference [6].

This anatomical localization of P-gp suggests that the efflux transporter is functionally operating to protect the tissues and organs against toxic xenobiotics via excretion into bile, urine, feces, and by preventing their accumulation in fetus, brain, and testes [11]. In general, these xenobiotics are structurally and pharmacologically unrelated neutral to positively charged hydrophobic compounds (Table 1) [12]. Furthermore, due to its strategic localization, P-gp is also suggested to play important role in the processes of absorption, distribution, metabolism, and excretion of drugs in humans and animals. In fact, Chen et al. reviewed various pharmacokinetic and pharmacodynamic data in Mdrla gene knockout mice and compared them to those of wild-type [13]. In general, a lack of Mdr1 resulted in higher area under the curve (AUC) and plasma concentrations of fexofenadine, ivermectine, tacrolimus, paclitaxel, etoposide, erythromycin, digoxin, saquinavir, nelfinavir, indinavir, and irinocetan [13]. The main role of P-gp in 
elevating the AUC and plasma concentrations of these drugs was attributed to increased intestinal absorption of these drugs upon oral administration in the Mdrla knockout mice [13]. The purpose of this review is to summarize the current knowledge about the role of P-gp in drug absorption, distribution, metabolism, excretion, and P-gp role in drug-drug-interactions and their clinical implications.

Table1. Examples of P-gp substrates of pharmaceutical use

\begin{tabular}{|l|l|}
\hline \multicolumn{1}{|c|}{ Drug class } & \multicolumn{1}{c|}{ Examples } \\
\hline Anticancer agents & $\begin{array}{l}\text { Daunorubicin, Doxorubicine, Etoposide, Irinotecan, } \\
\text { Paclitaxel, Vinblastine, Vincristine }\end{array}$ \\
\hline Antivirals & Indinavir, Nelfi navir, Ritonavir, Saquinavir \\
\hline $\mathrm{Ca}^{2+}$ channel blockers & Diltiazem, Nicardipine, Nifedipine, Verapamil \\
\hline Immunosupressives & Cyclosporin, Tacrolimus \\
\hline Steroids & $\begin{array}{l}\text { Cortisol, Dexamethasone, Estradiol, Progesterone, } \\
\text { Tamoxifen }\end{array}$ \\
\hline Miscellaneous & $\begin{array}{l}\text { Acetyldigoxin, Digoxin, Digitoxin, Erythromycin, Grepafl } \\
\text { oxacin, Ivermectine, Methyldigoxin, Quinidine }\end{array}$ \\
\hline
\end{tabular}

\section{DRUG ABSORPTION:}

Oral bioavailability of drugs was initially thought to be a function of absorption and phase I metabolism [14]. However, with the advancement in pharmacokinetics, it has become apparent that active efflux via P-gp in the small intestine is a major contributor to poor absorption and consequently low bioavailability [14]. The expression of P-gp appears to vary along the small intestine. In human intestine, Pgp is expressed on the apical surface of the columnar epithelial cells (Fig. 2) [15]. Mouly and Paine determined the P-gp expression by Western blotting across the human intestine and found that its expression increases progressively from proximal to distal regions with a maximum difference of 20-fold between stomach and ileum [15]. Arguably, intestinal P-gp appears to influence the peak concentration of orally administered drugs in the systemic circulation (Cmax) more than affecting the overall systemic exposure (AUC) [3]. The Cmax is affected by the extent of oral bioavailability $(\mathrm{F})$, which is the fraction of administered drug that reaches the systemic circulation in an intact form [2]. Previous studies have shown that oral bioavailability of cyclosporin in healthy human volunteers is increased from 0.293 to 0.651 upon co-administration of ketoconazole, a P-gp and cytochrome P450 3A4 (CYP3A4) inhibitor [16]. In general, absorption of a drug gets more complicated by the existence of the P-gp efflux transporter. In reality, a drug molecule that is a P-gp substrate is absorbed and readily crosses the epithelial cell membrane by simple diffusion [17]. Inside the cell, there are three possible fates for this drug molecule [17]: 1) it might continue to diffuse along the concentration gradient, and reaches mesenteric circulation, 2) it might be removed back to the lumen by the efflux transporters, or lastly 3) it might be subjected to intestinal metabolism ,Fig. 2. Thus, the net absorbed drug to the mesenteric circulation $=$ drug absorbed by influx - (drug extruded by efflux + drug metabolized by enzymes). The first evidence for the involvement of P-gp in drug absorption was first demonstrated in vitro using Caco-2 cells which are of human colon origin and have high expression of P-gp. It was demonstrated that basolateral-to-apical (B-to-A) transport of vinblastine and docetaxel was 10 - and 20 -fold higher than the A-to-B transport [18; 19]. Moreover, vinblastine, docetaxel, and small peptides A-to-B transport was significantly increased in the presence of the P-gp inhibitors, verapamil and MRK16 antibody [20; 21]. Caco2 cells have been also used to study the intestinal transport of cyclosporin. Similar to the data obtained with vinblastine and docetaxel, the Bto-A transport of cyclosporin was greater than the A-to-B transport. In addition, the A-to-B transport of cyclosporin increased and the B-toA transport decreased in the presence of P-gp inhibitors progesterone and chlorpromazine [22]. Although appreciable efforts have been made to investigate the role of P-gp in vitro, the direct evidence for the involvement of P-gp in drug absorption was derived from in vivo studies using the Mdr1a knockout mice. In these studies it was shown that the oral absorption of pacliataxel and consequently the plasma AUC were increased by 2- and 6-fold in the Mdrla knockout mice, compared to wild-type, after intravenous and oral drug administration, respectively [23]. The differences in fold increase between intravenous and oral drug 
administration could be attributed to a decrease in the elimination clearance of the former and an increase in the extent of drug absorption of the latter. An advantage of using the in vivo Mdrla knockout mice model is that it permits examining the intestinal excretion by interrupting the bile flow via gallbladder canulation [24]. Hence, with the continued studies on paclitaxel using the canulated mice, it was shown that $11 \%$ of the dose was excreted in the intestinal lumen within 90 min after intravenous administration of the drug in to Mdr1a wild-type mice [25]. Interestingly, only $2.5 \%$ of the dose was excreted in the intestinal lumen of Mdrla knockout gallbladder cannulated mice [25]. Mechanistically, biliary and urinary excretions were the main pathways examined. However, intestinal excretion should be given more attention.

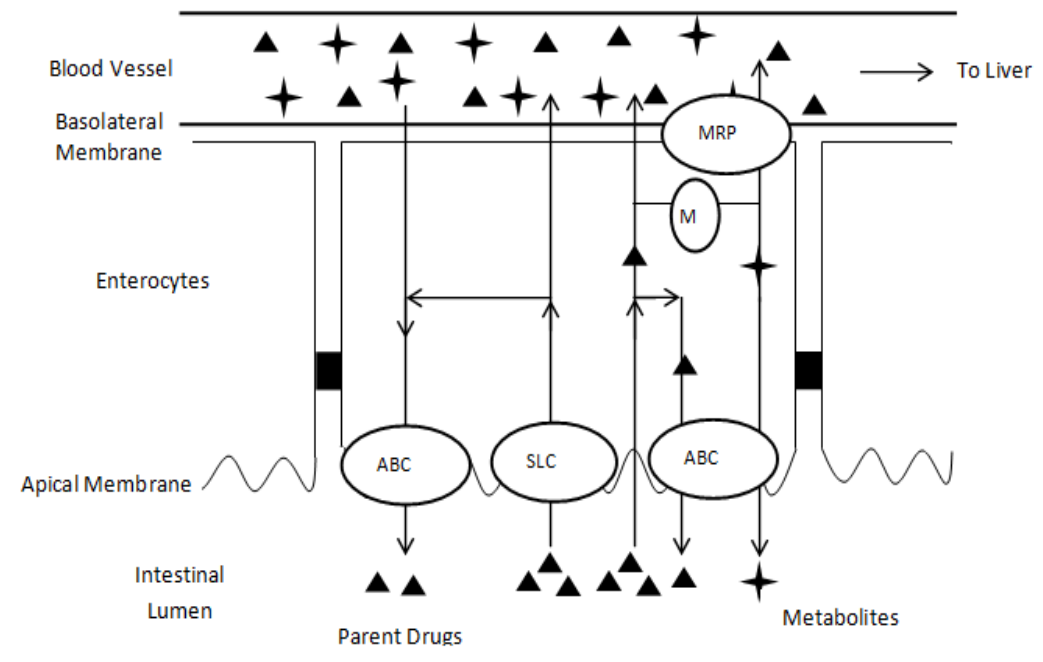

Figure2. Membrane transport of substrates for ABC efflux transporters in the intestine. Substrate molecules enter the cell from intestinal lumen into the cells by simple diffusion, facilitated diffusion or secondary active transport (SLCs) system. Fraction of these molecules is effluxed back to the lumen by ABC efflux transporters (such as P-gp) as it is or after metabolism (M) in the cells. MRPs transport substrates in the direction of bloodstream. Intracellular compounds escaped from the efflux or metabolism would enter the circulating bloodstream. Compounds in the bloodstream can be effluxed to intestinal lumen by ABCs expressed on the brush-border membrane. Adapted from [2].

Further evidence for the involvement of intestinal P-gp in drug absorption in humans was previously demonstrated when P-gp mRNA levels were inversely correlated with tacrolimus plasma concentration to oral dose ratio in living donor liver transplant and small-bowel transplant patients [26]. In another clinical study, it was shown that intestinal P-gp mRNA level is a potential determinant of cyclosporin oral dose in living donor liver transplant patients [27]. Similarly, duodenal P-gp mRNA levels were inversely correlated with AUC and Cmax of oral talinolol in healthy human subjects [28]. Unlike the direct evidence derived from Mdrla knockout mice, the involvement of MDR1 in drug absorption is extremely difficult to prove in human. Thus, the vast majority of studies conducted to examine the role of MDR1 in drug absorption in human often derive their conclusions based on the use of pharmacological inhibitors against P-gp. Therefore, these studies can only provide a qualitative but not quantitative assessment of the role of P-gp in drug absorption. Moreover, the absence of a specific P-gp inhibitor makes it more difficult to estimate the quantitative contribution of P-gp in drug absorption, since many of the P-gp inhibitors are CYP3A4 and other efflux transporters inhibitors. It is worth mentioning that, even in healthy volunteers who might be administered drugs which are P-gp substrates, the intra- and inter-patients variations in AUC and Cmax could be attributed to genetic polymorphisms of the P-gp and various disease states which might influence the P-gp efflux capacity [29]. More importantly, the drug-drug interactions, which will be covered later in this review, also play a role in the ADME profiles of drugs which are P-gp substrates. 


\section{DRUG DISTRIBUTION:}

Despite the fact that numerous efforts have been made towards the study of drug absorption, metabolism, and excretion processes, drug distribution has historically received much less attention. However, it has been shown that drug distribution is an important process in determining drug response where the transition between pharmacokinetics and pharmacodynamics occurs. Due to this loss of interest, drug distribution has become a pharmacokinetic orphan. This lack of attention in the pharmaceutical sciences community stems partly from the absence of useful experimental tools to examine the role of distribution in drug disposition. In spite of being neglected, drug distribution has become increasingly recognized as an important factor in determining drug disposition, especially in the brain and fetus [30]. The brain is different from other organs of the body in many aspects. One of the important features of brain is that it is anatomically separated from systemic blood circulation by the blood-brain-barrier (BBB) ,Fig3. [6]. Similarly, the only link between the fetus and mother is the placenta [29]. Both the BBB and the placenta express the P-gp to different extents, prohibiting the accumulation of toxins and P-gp substrates from being distributed to the brain and fetus, respectively.

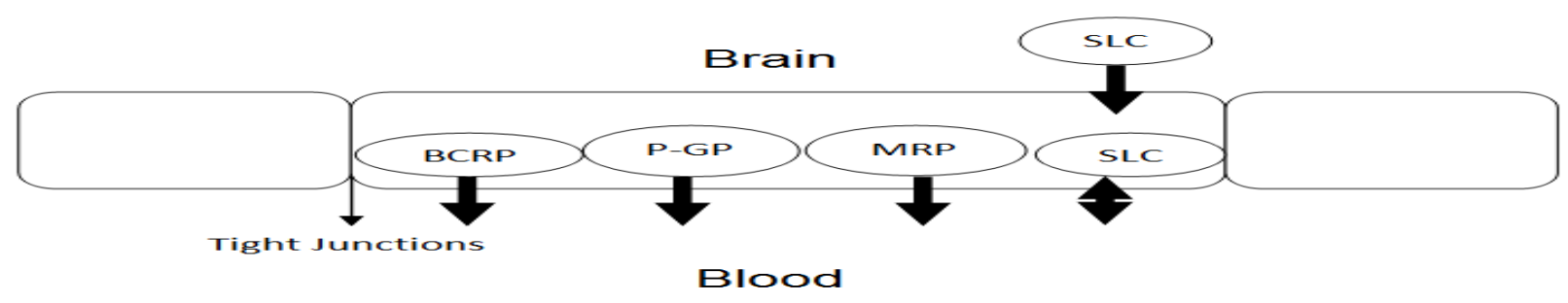

Figure 3: Drug transporter expression at the blood brain barrier. Modified from reference [78].

It has been long known that lipophilicity is required for BBB penetration. However, many well-known drugs exhibit lipophilicity and are still unable to cross the BBB. During the past twenty to thirty years these drugs were termed "outliers" [31] without knowing the reason behind this unusual phenomenon, hence the term "the fog that was not". It has now become apparent that poor BBB permeability of these drugs is in fact due to the presence of efflux transporters [31]. The P-gp in the BBB is a double-edged sword [30]; on one hand it limits the penetration of CNS-targeted drugs, and on the other hand it eliminates toxins from being disposed in the CNS. One of the best examples describing the pivotal role of P-gp in limiting CNS penetration of drugs is the antidiarrheal drug loperamide [32]. If permitted to enter the
CNS, loperamide is a potent opiate. However, being a substrate for P-gp, it is unable to cross the BBB. Similarly, the dopaminergic antagonist domperidone has been shown to be extruded by P-gp in the BBB; thus it has failed to be an effective antipsychotic [33]. Studies using the Mdrla knockout mice have shown that fexofenadine brain concentration was 9-fold higher than wild-type mice [34]. Similar studies on HIV protease inhibitors showed that brain concentrations and brain to plasma ratios of indinavir, nelfinavir, and saquinavir are significantly increased in Mdrla knockout mice compared to wild-type [35]. P-gp can be also involved in the cellular uptake and efflux of xenobiotics from placenta. P-gp has been shown to be expressed in the human placenta from the first trimester until delivery ,Fig. 4. [29].

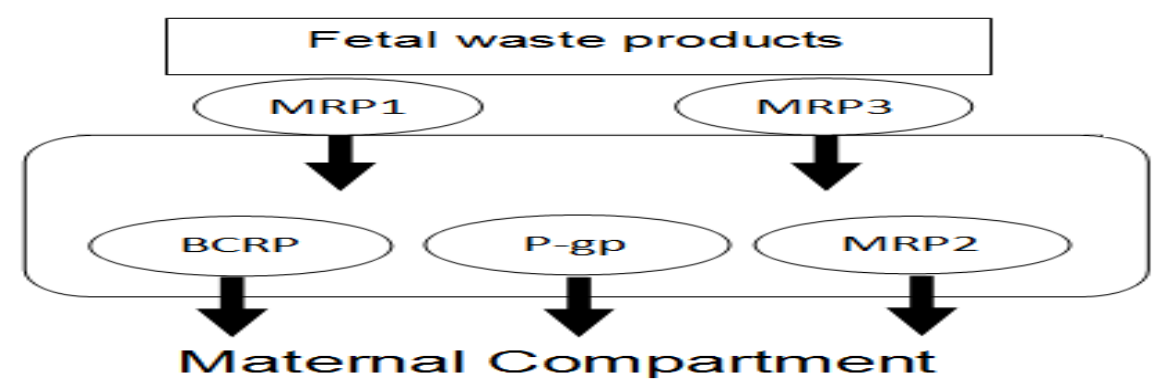

Figure 4. Drug transporter expression at the syncytiotrophoblast layer. Modified from reference [29]. 
Ayman O.S. El-Kadi et al

There are also several other efflux transporters in the placenta, yet P-gp dominates over other transporters. Conglomerates of studies have demonstrated that P-gp is involved in preventing entry of harmful substances to the fetus. Lankas et al. has clearly demonstrated that deficiency in placental P-gp in CF-1 mice resulted in a significant increase in avermectin induced birth defects such as cleft palate [36]. In particular, Mdrla knockout mice developed cleft palate that was not observed in the wild-type [36]. Smit et al. has also demonstrated that P-gp substrates typified by digoxin, saquinavir, and paclitaxel fetus concentrations were significantly increased by $2.5-, 6-$, and 16- fold, respectively in Mdr1a knockout mice [37]. Monoclonal antibody immunostaining showed a high expression of Pgp in trophoblasts of human placenta [38]. However, due to the ethical, moral and sometimes legal constraints, clinical trials are rarely, if not ever, conducted on pregnant women. Therefore, studies examining the role of P-gp in drug disposition across the placenta are now easily conducted using the cultured human placenta choriocarcinoma epithelial cells (BeWo cells) [39]. Studies performed on these cells have shown that B-to-A transport of vinblastine, vincristine, and digoxin was significantly greater than A-to-B transport [10]. Co-treatment of the cells with cyclosporin increased the A-to-B transport while lowering the B-to-A transport. Thus, it has become apparent that the presence of P-gp in human placenta acts to prevent the distribution of harmful substances, including drugs to the fetus.

\section{DRUG METABOLISM:}

It is widely accepted that the liver is the main site for drug metabolism because of its size and high content of drug metabolizing enzymes [40]. Besides the liver, the kidneys and small intestine, and other vital tissues may contribute significantly to the overall metabolism in the body [41]. In humans, CYP3A4 is the main enzyme responsible for hepatic and intestinal metabolism of a wide array of endogenous and exogenous chemical entities [41]. The fact that CYP3A4 and P-gp may synergistically act in the small intestine to decrease oral drug bioavailability is supported not only by their coexistence at sites of drug absorption, but also by the striking overlap in their substrates [42]. Given that a fraction of the extruded drug molecules are reabsorbed into enetrocytes, the repetitive extrusion/reabsorption process prolongs the intracellular residence of the molecule, increasing the probability that it gets exposed to CYP3A4-mediated drug metabolism [24]. Previous studies have shown that CYP3A4 is equally distributed in different regions of the liver [43]. In contrast, the distribution of CYP3A4 is variable along the length of the small intestine; it has been demonstrated that the expression of CYP3A4 progressively decreases from proximal to distal parts of the intestine with median values of 31,23 , and $17 \mathrm{pmol} / \mathrm{mg}$ microsomal protein in human duodenum, distal jejunum, and distal ileum, respectively [43]. However, this is not the only difference between CYP3A4 and P-gp expression in the small intestine, and liver and kidney. As such, in the liver and kidney, P-gp is localized on the luminal membrane of hepatic canaliculi facing the bile duct lumen or on the luminal brushborder membrane of renal proximal tubular cells facing the renal tubule lumen [44]. Thus, P-gp is present at the exit site of hepatocytes and renal epithelial cells. In other words, P-gp is exposed to drug molecules after being cellularly uptaken, distributed, and metabolized in both the liver and the kidney. One of the most important fooddrug interactions that are related to the interplay between P-gp and CYP3A4 is the one involving the intake of grapefruit juice with CYP3A and/or P-gp drug substrates. Based on erythromycin breath test, which is a surrogate marker for hepatic CYP3A4 activity, it was shown that the intake of grapefruit juice does not affect hepatic CYP3A4 levels [45]. In contrast, it was demonstrated that intestinal CYP3A4 is lowered by the intake of grapefruit juice [45]. For cyclosporine, it has been suggested that intestinal P-gp, rather than CYP3A4 is deeply involved in lowering its human intestinal availability [46]. To test this hypothesis, Edwards et al. examined the plasmaconcentration/time profiles of cyclosporine in volunteers who were given either grapefruit or Seville orange juice [47]. In this study, it was shown that intestinal CYP3A4 level was slightly decreased in the patients who received grapefruit juice but not Seville orange juice [47]. Interestingly, cyclosporine AUC and Cmax were significantly increased by the intake of grapefruit juice but not Seville orange juice [47]. It was previously thought that grapefruit inhibits CYP3A4 only. However, in this study the inhibition of CYP3A4 by grapefruit could not 
account for the significant increase in both AUC and Cmax of cyclosporine. Therefore, the authors suggested the presence of a potent P-gp inhibitor in grapefruit juice that was later confirmed by other studies [48; 49]. In addition to cyclosporine, grapefruit juice also increased the oral bioavailability of midazolam, felodipine, and saquinavir without affecting hepatic elimination of these drugs [50]. Therefore, by using grapefruit juice as an inhibitor of both CYP3A4 and P-gp, researchers were able to determine oral bioavailability of drugs that are substrates for both CYP3A4 and P-gp by comparing the oral AUC before and after the ingestion of grape fruit juice. However, later, specific P-gp or CYP3A inhibitors were used to dissect the role of each one separately.

In the last 15 to 20 years, there have been numerous studies conducted to prove the interplay between P-gp and CYP3A4. In one study, it was shown that the formation of metabolite 7 (M7) from indinavir, a substrate of both P-gp and CYP3A4, was 6-fold greater when the drug was applied at the apical side of the Caco-2 cells than when it was applied to the basolateral side $[51 ; 52]$. Similarly, the metabolism of cyclosporine in Caco-2 cells was higher from the apical side than from the basolateral side [53]. The data obtained with indinavir were confirmed in vivo as the intestinal first pass metabolism of indinavir increased from $6 \%$ to $34 \%$ in a group of rats administered dexamethasone, an inducer of both P-gp and CYP3A [54]. The 6-fold increase in intestinal first-pass metabolism of indinavir cannot be explained by the 2.5 -fold increase in intestinal CYP3A level only. An explanation for this controversy is that CYP3A and P-gp act synergistically to decrease oral bioavailability. There were also other in vitro studies on intestinal models that lend support to this interplay hypothesis.

In contrast to the interplay hypothesis, using Caco-2 cells transfected with CYP3A4 overexpressing vector, it was shown that the P-gp inhibitor LY335979 increased the formation rate of a major CYP3A4-mediated metabolite of saquinavir [52]. The authors suggested that this could be due to the increased cellular content of saquinavir via P-gp mediated efflux. However, the interpretation of this result is not straightforward since this metabolite is a P-gp substrate by itself. Thus, by inhibiting P-gp activity, the metabolite will readily accumulate inside the cells. Intriguingly, in a study performed in humans, a direct support to the interplay between CYP3A4 and P-gp in gut wall was demonstrated. In this study, the small intestine was perfused with quinidine by means of a multiluminal perfusion catheter in eight healthy volunteers [55]. It was shown that the dose-corrected plasma quinidine AUC from 0 to $3 \mathrm{~h}$ was negatively correlated with both intestinal P-gp and CYP3A4 contents [56]. In addition, dose-corrected intraluminal quinidine concentrations were positively correlated with intestinal P-gp expression. The interplay hypothesis has been also shown to be valid in liver [56]. Lau et al. demonstrated through elegant experiments that, in an isolated perfused rat liver model, digoxin CYP3A-mediated metabolism increased in animals treated with quinidine, a P-gp inhibitor, compared with control animals [57]. It was concluded that through inhibiting the biliary secretion of digoxin, quinidine increases the digoxin metabolism by prolonging its exposure to hepatic CYP3A. Theoretically, the interplay between P-gp and CYP3A4 is an attractive subject to investigate. However, studies carried out to prove that the synergism between CYP3A4 and P-gp occurs at the transcriptional regulation level have failed. Therefore, the functional interaction between both CYP3A4 and P-gp warrants further studies.

\section{DRUG ELIMINATION:}

Drugs are generally eliminated from the body through metabolism and/or excretion. Both liver and kidney facilitate the excretion of unchanged drugs and their metabolites. Principally, biliary excretion and renal tubular excretion are functionally similar but their operating mechanisms are different. For example, in biliary excretion the drug needs to traverse the basolateral membrane of the hepatocytes by passive diffusion and/or transporters [58]. Once inside the hepatocyte, the diffused drug will move along the concentration gradient to reach the apical (canalicular) membrane, where P-gp "sees" the drug molecule, perhaps for the last time, before it is pumped into the bile [58]. Through its journey inside the hepatocyte, the drug molecule is exposed to metabolism which will be facilitated by phase I and phase II drug metabolizing enzymes. Therefore, hepatic cellular uptake, intracellular diffusion, metabolism, and efflux transport have to be 
taken in-to account when evaluating biliary excretion of drugs. Similarly, renal uptake of drugs occurs at the basolateral membrane of the epithelial cells as a first step in renal excretion [59]. Also, metabolism might occur to the drug molecule inside the renal epithelial cell before it reaches the luminal brush-border membrane where P-gp subsequently pumps it to the urine.

The involvement of P-gp in biliary excretion of drugs was previously demonstrated in vitro, in vivo, and in clinical studies. In vitro studies using canalicular membrane vesicles and perfused rat liver showed that the transport of daunomycin is ATP-dependent $[60 ; 61]$. Furthermore, it was shown that inhibition of Pgp using verapamil inhibited daunomycin transport, suggesting involvement of P-gp in the biliary excretion of daunomycin [61]. Similarly, using perfused rat liver, vincristine and doxorubicin elimination was shown to be through biliary excretion [62]. More convincing data regarding the importance of P-gp in biliary excretion have been generated by studying digoxin metabolism using Mdrla knockout mice. Digoxin is mainly excreted as a nonmetabolized drug in the urine and the bile [56]. Importantly, digoxin has a narrow therapeutic window, and even modest changes in its biliary or renal clearance can lead to untoward side effects. The biliary clearance of digoxin was 3fold higher in Mdrla wild-type mice compared to knockout, indicating that P-gp is a key player in the biliary excretion of digoxin in mice [63]. In agreement with digoxin, vinblastine, vecuronium and doxorubicin biliary clearance was 3- to 5-fold greater in Mdr1a wild-type mice compared to knockout [24]. In rat models, dexamethasone pretreatment increased biliary clearance of rhodamine-123, a P-gp substrate, by 8 -fold [64]. Due to the extreme difficulties in obtaining bile from humans, the clinical studies evaluating the role of P-gp in biliary excretion are limited. In one clinical study, systemic digoxin exposure, as determined by AUC was reduced during rifampin treatment partly due to an increase in digoxin biliary excretion [65]. To the opposite, inhibition of P-gp by quinidine and GF120918 significantly decreased digoxin and doxorubicin biliary excretion [66]. In contrast to the biliary excretion process which involves just one excretion step, the renal excretion usually involves three processes: glomerular filtration, renal tubular secretion, and reabsorption from renal tubular lumen [24]. Therefore, the relationship between renal clearance (CLR) and these processes can be expressed by the following equation:

$\mathrm{CLR}=\mathrm{fu} . \mathrm{GFR}+\mathrm{CLs}-\mathrm{CLRA}$ (equation. 1)By rearrangement of equation.1: CLR/(fu . GFR) = $1+[($ CLs - CLRA $) /(f u$. GFR) $]$ (equation. 2) GFR, CLs, CLRA, and fu are in order: glomerular filtration rate, secretion clearance, reabsorption clearance, and unbound fraction of drug in plasma. GFR is a passive process while secretion and reabsorption are active processes involving different transporters. In vitro systems have proven to be a valuable tool in determining the role of P-gp in tubular secretion. For example, the human MDR1 gene-transfected Madin-Darby canine kidney (MDCK), and the porcine kidney epithelial cells (LLC-PK1) are the two most widely used models for the study of renal P-gp function [3]. The reason behind the extensive use of these cells is that the United States Food and Drug Administration (USFDA) guidance for industry recommends that bidirectional transport studies be conducted using Caco-2, MDR1-MDCK, or MDR1-LLCPK1 recombinant cell lines to identify P-gp substrates and inhibitors [3]. The B-to-A transepithelial transport of digoxin, cyclosporin, and vinblastine was greater than the A-to-B transport in LLC-PK1 cells $[67 ; 68]$. Similarly, the B-to-A transport of vinblastine was 6-fold greater than the A-to-B transport in MDCK cells [69]. Another important in vitro technique that was used to investigate the role of P-gp in tubular secretion is the isolated perfused kidney. In associating the results obtained with this technique and equation 2 , one can determine the contribution of each process in the overall renal clearance. For example, when the CLR/(fu . GFR) of an administered drug is greater than unity, this means that tubular secretion of the drug occurs. Inversely, when the CLR/(fu . GFR) of an administered drug is less than unity, reabsorption of the drug from the tubular lumen occurs [24]. Using this approach, Hori et al. showed that digoxin was actively secreted in the isolated perfused rat kidney [70]. In addition, when quinidine and verapamil were added, they inhibited the tubular secretion of digoxin [70].

In vivo, the renal clearance of digoxin was compared in Mdr1a knockout and wild-type mice. Expectedly, the renal clearance of digoxin in Mdrla wild-type was 3-fold higher than the knockout mice [63]. In contrast to digoxin, the renal clearance of nonmetabolized doxorubicin 
and three basic compounds (vecuronium, azidoprocainamide, and tributyltrimethylammonium) was higher in the Mdr1 knockout mice compared to wild-type [71]. The reason for this conflicting data is that other transporter systems may be involved in the renal clearance of doxorubicin and these basic compounds, and the expression of these transporter systems might be elevated as a compensatory mechanism to the loss of Mdr1

\section{P-GP ROLE IN DRUG-DRUG INTERACTIONS AND CLINICAL IMPLICATIONS}

Several prominent drugs have been withdrawn from the market because of their serious adverse effects as a result of CYP-mediated interactions [72]. Like CYP-mediated interactions, P-gpmediated interactions can occur if a substrate and inhibitor of P-gp are co-administered. The inhibition of P-gp transport of a drug by another drug could potentially result from either competition for drug-binding sites on the P-gp or from blockage of ATP hydrolysis process. For example, verapamil inhibits P-gp drug transport in a competitive manner without affecting ATP hydrolysis $[73 ; 74 ; 75]$. In contrast, vanadate interacts with the ATP hydrolysis sites of P-gp without interacting with the substrate binding site [75]. Interestingly, cyclosporin inhibits P-gp by interfering with both substrate binding and ATP hydrolysis $[73 ; 74 ; 75]$. In principal, the inhibition of P-gp-mediated transport usually results in an increased bioavailability, decreased clearance, hence markedly elevated AUC of the affected drug [24]. Although the use of effective P-gp inhibitors such as LY335979, valspodar, and FG-120918 may improve treatment of cancers, which are rich in multi-drug resistance efflux transporters, these inhibitors lack specificity towards cancerous tissues [24]. In other words, the arbitrary use of these P-gp inhibitors will result in increased toxicity in normal tissues. For example, the antiviral drug ritonavir which inhibits P-gp activity, increased digoxin AUC, prolonged its residence time, and ultimately increased its toxicity [3]. Diltiazem, another P-gp inhibitor, increased the plasma concentration and associated adverse effects of the neurosuppressive agent tacrolimus [3]. The drug-drug interactions although detrimental, have been favorably used for its benefits in some clinical cases. For example tiprinavir, an HIV protease inhibitor, is co-administered with ritonavir [76; 77]. It has been shown that tiprinavir is a substrate and inducer of both CYP3A4 and P-gp. Ritonavir in this combination will act as a pharmacokinetic booster as it will decrease the CYP3A4mediated metabolism and the P-gp-mediated transport of tiprinavir. Interestingly, this combination of tipranavir/ritonavir affects other drugs pharmacokinetic parameters. For example, co-administration of loperamide with steadystate tipranavir/ritonavir decreased loperamide AUC and Cmax [76; 77]. However, coadministration of loperamide with steady-state ritonavir only resulted in increased loperamide AUC and Cmax [76; 77]. In addition, steadystate tipranavir/ritonavir increased clarithromycin AUC0-12 and $\mathrm{Cp} 12 \mathrm{~h}$ with no substantial change in Cmax. A possible explanation to this observation with clarithromycin is that tipranavir is a P-gp inducer, and the small dose of ritonavir cannot compensate for the P-gp induction caused by tipranavir [3]. Given that clarithromycin is a Pgp substrate, it is extruded back to intestinal lumen as unabsorbed drug by the effect of the induced P-gp. Various challenges remain at large in determining the clinical significance of drug transporters such as P-gp, and in predicting the interplay between these transporters and various drug metabolizing enzymes, such as CYP3A. In either case, drug absorption, distribution, metabolism, and elimination properties need to be accurately evaluated for clinical efficacy and safety.

\section{ACKNOWLEDGMENTS:}

This work was supported by Natural Sciences and Engineering Research Council of Canada (NSERC) Discovery Grant RGPIN 250139-12 to A.O.S. A.A-M. is the recipient of Alberta Ingenuity Graduate Scholarship and Izaak Walton Killam memorial graduate Scholarship.

\section{REFERENCES:}

1) Kis O, Robillard K, Chan GN, Bendayan R, The complexities of antiretroviral drug-drug interactions: role of $\mathrm{ABC}$ and SLC transporters. Trends Pharmacol Sci. 2010; 31: 22-35. DOI:S0165-6147(09)00165-5

2) Murakami $T$, Takano $M$, Intestinal efflux transporters and drug absorption. Expert Opin Drug Metab Toxicol. 2008; 4: 923-939. DOI:10.1517/17425255.4.7.923 
3) Zhang L, Zhang YD, Strong JM, Reynolds KS, Huang SM, A regulatory viewpoint on transporter-based drug interactions. Xenobiotica. 2008; 38: 709-724. DOI:795430934

4) Juliano RL, Ling V, A surface glycoprotein modulating drug permeability in Chinese hamster ovary cell mutants. Biochim Biophys Acta. 1976; 455:152-162. DOI:0005-2736 (76) $90160-7$

5) Chinn LW, Kroetz DL, ABCB1 pharmacogenetics: progress, pitfalls, and promise. Clin Pharmacol Ther. 2007; 81: 265269. DOI:6100052

6) Kannan P, John C, Zoghbi SS, Halldin C, Gottesman MM, Innis RB, Hall MD, Imaging the function of P-glycoprotein with radiotracers: pharmacokinetics and in vivo applications. Clin Pharmacol Ther. 2009; 86: 368-377. DOI:clpt2009138

7) Bow DA, Perry JL, Miller DS, Pritchard JB, Brouwer KL, Localization of P-gp (Abcb1) and Mrp2 (Abcc2) in freshly isolated rat hepatocytes. Drug Metab Dispos. 2008; 36: 198202. DOI:dmd.107.018200

8) Lash LH, Putt DA, Cai H, Membrane transport function in primary cultures of human proximal tubular cells. Toxicology. 2006; 228: 200-218. DOI:S0300-483X(06)00547-6

9) Mukhopadhyay T, Batsakis JG, Kuo MT, Expression of the mdr (P-glycoprotein) gene in Chinese hamster digestive tracts. J Natl Cancer Inst. 1988; 80: 269-275.

10) Ushigome $F$, Takanaga $H$, Matsuo $H$, Yanai $\mathrm{S}$, Tsukimori $\mathrm{K}$, Nakano $\mathrm{H}$, Uchiumi $\mathrm{T}$, Nakamura T, Kuwano M, Ohtani H, Sawada Y, Human placental transport of vinblastine, vincristine, digoxin and progesterone: contribution of P-glycoprotein. Eur J Pharmacol. 2000; 408: 1-10. DOI:S0014-2999(00)00743-3

11) Staud F, Ceckova M, Micuda S, Pavek P, Expression and function of p-glycoprotein in normal tissues: effect on pharmacokinetics. Methods Mol Biol. 2010; 596: 199-222. DOI:10.1007/978-1-60761-416-6_10

12) Loo TW, Bartlett MC, Clarke DM, Transmembrane segment 7 of human Pglycoprotein forms part of the drug-binding pocket. Biochem J. 2006; 399: 351-359. DOI:BJ20060715

13) Chen C, Liu X, Smith BJ, Utility of Mdr1gene deficient mice in assessing the impact of $\mathrm{P}$ glycoprotein on pharmacokinetics and pharmacodynamics in drug discovery and development. Curr Drug Metab. 2003; 4: 272291.

14) Padowski JM, Pollack GM, Pharmacokinetic and pharmacodynamic implications of $\mathrm{P}$ glycoprotein modulation. Methods Mol Biol. 2010; 596: 359-384. DOI:10.1007/978-1-60761416-6 16

15) Mouly S, Paine MF, P-glycoprotein increases from proximal to distal regions of human small intestine. Pharm Res. 2003; 20: 1595-1599.

16) $\mathrm{Wu} \mathrm{CY}$, Benet LZ, Hebert MF, Gupta SK, Rowland M, Gomez DY, Wacher VJ, Differentiation of absorption and first-pass gut and hepatic metabolism in humans: studies with cyclosporine. Clin Pharmacol Ther. 1995; 58: 492-497. DOI:0009-9236(95)90168-X

17) ] Suzuki H, Sugiyama Y, Role of metabolic enzymes and efflux transporters in the absorption of drugs from the small intestine. Eur J Pharm Sci. 2000; 12: 3-12. DOI:S09280987(00)00178-0

18) Takanaga $H$, Ohnishi A, Matsuo $H$, Sawada Y, Inhibition of vinblastine efflux mediated by P-glycoprotein by grapefruit juice components in caco-2 cells. Biol Pharm Bull. 1998; 21: 1062-1066.

19) Wils $P$, Phung-Ba V, Warnery A, Lechardeur D, Raeissi S, Hidalgo IJ, Scherman D, Polarized transport of docetaxel and vinblastine mediated by P-glycoprotein in human intestinal epithelial cell monolayers. Biochem Pharmacol. 1994; 48: 1528-1530. DOI:0006-2952(94)90580-0

20) ] Hunter J, Jepson MA, Tsuruo T, Simmons NL, Hirst BH, Functional expression of Pglycoprotein in apical membranes of human intestinal Caco-2 cells. Kinetics of vinblastine secretion and interaction with modulators. J Biol Chem. 1993; 268: 14991-14997.

21) Hunter J, Hirst BH, Simmons NL, Drug absorption limited by P-glycoprotein-mediated secretory drug transport in human intestinal epithelial Caco-2 cell layers. Pharm Res. 1993; 10: 743-749.

22) Augustijns PF, Bradshaw TP, Gan LS, Hendren RW, Thakker DR, Evidence for a polarized efflux system in CACO-2 cells capable of modulating cyclosporin A transport. Biochem Biophys Res Commun. 1993; 197 : 360-365. DOI:S0006291X83724873

23) Lagas JS, Vlaming ML, van Tellingen $O$, Wagenaar E, Jansen RS, Rosing H, Beijnen JH, Schinkel AH, Multidrug resistance protein 2 is an important determinant of paclitaxel 
pharmacokinetics. Clin Cancer Res. 2006; 12: 6125-6132. DOI:12/20/6125

24) Lin JH, Yamazaki M, Role of P-glycoprotein in pharmacokinetics: clinical implications. Clin Pharmacokinet. 2003; 42: 59-98. DOI:420103 [pii]

25) Hoffmeyer S, Burk O, von Richter O, Arnold HP, Brockmoller J, Johne A, Cascorbi I, Gerloff T, Roots I, Eichelbaum M, Brinkmann U, Functional polymorphisms of the human multidrug-resistance gene: multiple sequence variations and correlation of one allele with $\mathrm{P}$ glycoprotein expression and activity in vivo. Proc Natl Acad Sci U S A. 2000; 97: 3473-3478. DOI:10.1073/pnas.050585397

26) Lo A, Burckart GJ, P-glycoprotein and drug therapy in organ transplantation. J Clin Pharmacol. 1999; 39: 995-1005.

27) Masuda S, Goto $M$, Kiuchi T, Uemoto $S$, Kodawara T, Saito H, Tanaka K, Inui K, Enhanced expression of enterocyte Pglycoprotein depresses cyclosporine bioavailability in a recipient of living donor liver transplantation. Liver Transpl. 2003; 9: 11081113. DOI:10.1053/jlts.2003.50179

28) Siegmund W, Ludwig K, Engel G, Zschiesche M, Franke G, Hoffmann A, Terhaag B, Weitschies W, Variability of intestinal expression of P-glycoprotein in healthy volunteers as described by absorption of talinolol from four bioequivalent tablets. J Pharm Sci. 2003; 92: 604-610. DOI:10.1002/jps.10327

29) Behravan J, Piquette-Miller M, Drug transport across the placenta, role of the $\mathrm{ABC}$ drug efflux transporters. Expert Opin Drug Metab Toxicol. 2007; 3: 819-830. DOI:10.1517/17425255.3.6.819

30) Glavinas H, Krajcsi P, Cserepes J, Sarkadi B, The role of $\mathrm{ABC}$ transporters in drug resistance, metabolism and toxicity. Curr Drug Deliv. 2004; 1: 27-42.

31) Miller DS, Bauer B, Hartz AM, Modulation of P-glycoprotein at the blood-brain barrier: opportunities to improve central nervous system pharmacotherapy. Pharmacol Rev. 2008; 60: 196-209. DOI:pr.107.07109

32) Seneca N, Zoghbi SS, Shetty HU, Tuan E, Kannan P, Taku A, Innis RB, Pike VW, Effects of ketoconazole on the biodistribution and metabolism of $[11 \mathrm{C}]$ loperamide and $[11 \mathrm{C}] \mathrm{N}-$ desmethyl-loperamide in wild-type and P-gp knockout mice. Nucl Med Biol. 2010; 37: 335345. DOI:S0969-8051(09)00300-X
33) Dan Y, Murakami H, Koyabu N, Ohtani H, Sawada Y, Distribution of domperidone into the rat brain is increased by brain ischaemia or treatment with the P-glycoprotein inhibitor verapamil. J Pharm Pharmacol. 2002; 54: 729733.

34) Kitamura $Y$, Koto $H$, Matsuura $S$, Kawabata $\mathrm{T}$, Tsuchiya $\mathrm{H}$, Kusuhara $\mathrm{H}$, Tsujimoto $\mathrm{H}$, Sugiyama Y, Modest effect of impaired Pglycoprotein on the plasma concentrations of fexofenadine, quinidine, and loperamide following oral administration in collies. Drug Metab Dispos. 2008; 36: 807-810. DOI:dmd.107.017624

35) Kim RB, Fromm MF, Wandel C, Leake B, Wood AJ, Roden DM, Wilkinson GR, The drug transporter P-glycoprotein limits oral absorption and brain entry of HIV-1 protease inhibitors. J Clin Invest. 1998; 101: 289-294. DOI:10.1172/JCI1269

36) Lankas GR, Wise LD, Cartwright ME, Pippert T, Umbenhauer DR, Placental Pglycoprotein deficiency enhances susceptibility to chemically induced birth defects in mice. Reprod Toxicol. 1998; 12: 457-463. DOI:S0890623898000276

37) Smit JW, Huisman MT, van Tellingen O, Wiltshire HR, Schinkel AH, Absence or pharmacological blocking of placental Pglycoprotein profoundly increases fetal drug exposure. J Clin Invest. 1999; 104: 1441-1447. DOI:10.1172/JCI7963

38) Tanabe $M$, Ieiri I, Nagata $N$, Inoue $K$, Ito $S$, Kanamori Y, Takahashi M, Kurata Y, Kigawa J, Higuchi S, Terakawa N, Otsubo K, Expression of P-glycoprotein in human placenta: relation to genetic polymorphism of the multidrug resistance (MDR)-1 gene. J Pharmacol Exp Ther. 2001; 297: 1137-1143.

39) Ushigome $F$, Takanaga $H$, Matsuo $H$, Tsukimori K, Nakano H, Ohtani H, Sawada Y, Uptake mechanism of valproic acid in human placental choriocarcinoma cell line (BeWo). Eur J Pharmacol. 2001; 417: 169-176. DOI:S0014299901009128

40) von Bahr C, Groth CG, Jansson $H$, Lundgren G, Lind M, Glaumann H, Drug metabolism in human liver in vitro: establishment of a human liver bank. Clin Pharmacol Ther. 1980; 27: 711725. DOI:0009-9236(80)90290-8

41) Nebert DW, Dalton TP, The role of cytochrome P450 enzymes in endogenous signalling pathways and environmental 
carcinogenesis. Nat Rev Cancer. 2006; 6: 947960. DOI:10.1038/nrc2015

42) Srinivas NR, Dual drug interactions via Pglycoprotein (P-gp)/ cytochrome P450 (CYP3A4) interplay: recent case study of oral atorvastatin and verapamil. Eur $\mathrm{J}$ Clin Pharmacol. 2008; 64: 1135-1136. DOI:10.1007/s00228-008-0512-8

43) Berggren S, Gall C, Wollnitz N, Ekelund M, Karlbom U, Hoogstraate J, Schrenk D, Lennernas $\mathrm{H}$, Gene and protein expression of Pglycoprotein, MRP1, MRP2, and CYP3A4 in the small and large human intestine. Mol Pharm. 2007; 4: 252-257. DOI:10.1021/mp0600687

44) Thiebaut $F$, Tsuruo $T$, Hamada $H$, Gottesman MM, Pastan I, Willingham MC, Cellular localization of the multidrug-resistance gene product P-glycoprotein in normal human tissues. Proc Natl Acad Sci U S A. 1987; 84: 7735-7738. 45) Culm-Merdek KE, von Moltke LL, Gan L, Horan KA, Reynolds R, Harmatz JS, Court MH, Greenblatt DJ, Effect of extended exposure to grapefruit juice on cytochrome P450 3A activity in humans: comparison with ritonavir. Clin Pharmacol Ther. 2006; 79: 243-254. DOI:S0009-9236(05)00515-1

46) Lown KS, Mayo RR, Leichtman AB, Hsiao HL, Turgeon DK, Schmiedlin-Ren P, Brown MB, Guo W, Rossi SJ, Benet LZ, Watkins PB, Role of intestinal P-glycoprotein (mdrl) in interpatient variation in the oral bioavailability of cyclosporine. Clin Pharmacol Ther. 1997; 62: 248-260. DOI:S0009-9236(97)90027-8

47) Edwards DJ, Fitzsimmons ME, Schuetz EG, Yasuda K, Ducharme MP, Warbasse LH, Woster PM, Schuetz JD, Watkins P, 6',7'Dihydroxybergamottin in grapefruit juice and Seville orange juice: effects on cyclosporine disposition, enterocyte CYP3A4, and Pglycoprotein. Clin Pharmacol Ther. 1999; 65: 237-244. DOI:S0009-9236(99)70102-5

48) de Castro WV, Mertens-Talcott S, Derendorf $\mathrm{H}$, Butterweck V, Grapefruit juice-drug interactions: Grapefruit juice and its components inhibit P-glycoprotein (ABCB1) mediated transport of talinolol in Caco-2 cells. J Pharm Sci. 2007; 96: 2808-2817. DOI:10.1002/jps.20975

49) Wang EJ, Casciano CN, Clement RP, Johnson WW, Inhibition of P-glycoprotein transport function by grapefruit juice psoralen. Pharm Res. 2001; 18: 432-438.

50) Lilja JJ, Raaska K, Neuvonen PJ, Effects of grapefruit juice on the pharmacokinetics of acebutolol. Br J Clin Pharmacol. 2005; 60: 659663. DOI:BCP2489

51) Hochman JH, Chiba M, Yamazaki M, Tang $\mathrm{C}$, Lin JH, P-glycoprotein-mediated efflux of indinavir metabolites in Caco-2 cells expressing cytochrome P450 3A4. J Pharmacol Exp Ther. 2001; 298: 323-330.

52) Mouly SJ, Paine MF, Watkins PB, Contributions of CYP3A4, P-glycoprotein, and serum protein binding to the intestinal first-pass extraction of saquinavir. J Pharmacol Exp Ther. 2004; 308: 941-948. DOI:10.1124/jpet.103.056390

53) Fricker G, Drewe J, Huwyler J, Gutmann H, Beglinger C, Relevance of p-glycoprotein for the enteral absorption of cyclosporin A: in vitro-in vivo correlation. Br J Pharmacol. 1996; 118: 1841-1847.

54) Lin JH, Chiba M, Chen IW, Nishime JA, deLuna FA, Yamazaki M, Lin YJ, Effect of dexamethasone on the intestinal first-pass metabolism of indinavir in rats: evidence of cytochrome P-450 3A [correction of P-450 A] and p-glycoprotein induction. Drug Metab Dispos. 1999; 27: 1187-1193.

55) Kivisto KT， Niemi M, Fromm MF, Functional interaction of intestinal CYP3A4 and P-glycoprotein. Fundam Clin Pharmacol. 2004; 18: 621-626. DOI:FCP291

56) Drescher S, Glaeser H, Murdter T, Hitzl M, Eichelbaum M, Fromm MF, P-glycoproteinmediated intestinal and biliary digoxin transport in humans. Clin Pharmacol Ther. 2003; 73: 223231. DOI: $10.1067 / \mathrm{mcp} .2003 .27$

57) Lau YY, Wu CY, Okochi H, Benet LZ, Ex situ inhibition of hepatic uptake and efflux significantly changes metabolism: hepatic enzyme-transporter interplay. J Pharmacol Exp Ther. 2004; 308: 1040-1045. DOI:10.1124/jpet.103.061770

58) Pang KS, Weiss M, Macheras $P$, Advanced pharmacokinetic models based on organ clearance, circulatory, and fractal concepts. Aaps J. 2007; 9: $\quad$ E268-283. DOI:10.1208/aapsj0902030

59) Hagenbuch B, Drug uptake systems in liver and kidney: a historic perspective. Clin Pharmacol Ther. 2010; 87: 39-47. DOI:clpt2009235

60) Kitamura $T$, Jansen $P$, Hardenbrook C, Kamimoto Y, Gatmaitan Z, Arias IM, Defective ATP-dependent bile canalicular transport of organic anions in mutant (TR-) rats with 
conjugated hyperbilirubinemia. Proc Natl Acad Sci U S A. 1990; 87: 3557-3561.

61)] Kwon Y, Kamath AV, Morris ME, Inhibitors of P-glycoprotein-mediated daunomycin transport in rat liver canalicular membrane vesicles. J Pharm Sci. 1996; 85: 935939. DOI:10.1021/js9600540

62) Booth CL, Brouwer KR, Brouwer KL, Effect of multidrug resistance modulators on the hepatobiliary disposition of doxorubicin in the isolated perfused rat liver. Cancer Res. 1998; 58: 3641-3648.

63) Kawahara M, Sakata A, Miyashita T, Tamai I, Tsuji A, Physiologically based pharmacokinetics of digoxin in mdrla knockout mice. J Pharm Sci. 1999; 88: 1281-1287. DOI:10.1021/js 9901763

64) Yumoto R, Murakami T, Sanemasa M, Nasu R, Nagai J, Takano M, Pharmacokinetic interaction of cytochrome P450 3A-related compounds with rhodamine 123, a Pglycoprotein substrate, in rats pretreated with dexamethasone. Drug Metab Dispos. 2001; 29: 145-151.

65) Greiner B, Eichelbaum M, Fritz P, Kreichgauer HP, von Richter O, Zundler J, Kroemer HK, The role of intestinal Pglycoprotein in the interaction of digoxin and rifampin. J Clin Invest. 1999; 104: 147-153. DOI:10.1172/JCI6663

66) Annaert PP, Turncliff RZ, Booth CL, Thakker DR, Brouwer KL, P-glycoproteinmediated in vitro biliary excretion in sandwichcultured rat hepatocytes. Drug Metab Dispos. 2001; 29: 1277-1283.

67) Yamazaki M, Neway WE, Ohe T, Chen I, Rowe JF, Hochman JH, Chiba M, Lin JH, In vitro substrate identification studies for $\mathrm{p}$ glycoprotein-mediated transport: species difference and predictability of in vivo results. $\mathrm{J}$ Pharmacol Exp Ther. 2001; 296: 723-735.

68) Chu XY, Bleasby K, Yabut J, Cai X, Chan GH, Hafey MJ, Xu S, Bergman AJ, Braun MP, Dean DC, Evers R, Transport of the dipeptidyl peptidase-4 inhibitor sitagliptin by human organic anion transporter 3 , organic anion transporting polypeptide $4 \mathrm{C} 1$, and multidrug resistance P-glycoprotein. J Pharmacol Exp Ther. 2007; 321: 673-683. DOI:jpet.106.116517
69) Horio M, Chin KV, Currier SJ, Goldenberg S, Williams C, Pastan I, Gottesman MM, Handler J, Transepithelial transport of drugs by the multidrug transporter in cultured MadinDarby canine kidney cell epithelia. J Biol Chem. 1989; 264: 14880-14884.

70) Hori R, Okamura N, Aiba T, Tanigawara Y, Role of P-glycoprotein in renal tubular secretion of digoxin in the isolated perfused rat kidney. $\mathrm{J}$ Pharmacol Exp Ther. 1993; 266: 1620-1625.

71) ] Smit JW, Schinkel AH, Weert B, Meijer DK, Hepatobiliary and intestinal clearance of amphiphilic cationic drugs in mice in which both mdrla and mdrlb genes have been disrupted. $\mathrm{Br}$ J Pharmacol. 1998; 124: 416-424. DOI:10.1038/sj.bjp.0701845

72) Lin JH, CYP induction-mediated drug interactions: in vitro assessment and clinical implications. Pharm Res. 2006; 23: 1089-1116. DOI:10.1007/s11095-006-0277-7

73) Tamai I, Safa AR, Azidopine noncompetitively interacts with vinblastine and cyclosporin A binding to P-glycoprotein in multidrug resistant cells. J Biol Chem. 1991; 266: 16796-16800.

74) Ramachandra M, Ambudkar SV, Chen D, Hrycyna CA, Dey S, Gottesman MM, Pastan I, Human P-glycoprotein exhibits reduced affinity for substrates during a catalytic transition state. Biochemistry. 1998; 37: 5010-5019. DOI:10.1021/bi973045u

75) Senior AE, al-Shawi MK, Urbatsch IL, The catalytic cycle of P-glycoprotein. FEBS Lett. 1995; 377: 285-289. DOI:0014-5793(95)01345-8

76) Schinkel AH, Wagenaar E, Mol CA, van Deemter L, P-glycoprotein in the blood-brain barrier of mice influences the brain penetration and pharmacological activity of many drugs. $J$ Clin Invest. 1996; 97: 2517-2524. DOI:10.1172/JCI118699

77) Zhang L, Strong JM, Qiu W, Lesko LJ, Huang SM, Scientific perspectives on drug transporters and their role in drug interactionst. Mol Pharm. 2006; 3: 62-69.

78) Urquhart BL, Kim RB, Blood-brain barrier transporters and response to CNS-active drugs. Eur J Clin Pharmacol. 2009; 65: 1063-1070. DOI:10.1007/s00228-009-0714-8 